\title{
Setting New Agenda: Critical Study of Perspectives of CSR Practices in Indian Private Corporate Hospitals
}

\author{
Dr. Arundhati Ninawe \\ Associate Professor, HoD , Smt. L.R.T. College of Commerce, Akola (Maharashtra State)
}

\begin{abstract}
Health care service is profession as well as act of social welfare and devotion towards mankind. As a professional ethics health care centres have been adopting CSR practices. The present research study is an investigation of CSR (Corporate Social Responsibility) practices and it examined the different CSR practices, its significance, obstacles and future challenges before Indian private corporate hospitals. The concept of CSR is now firmly rooted on the agenda of hospital services. But in order to move it from theory to action there are many obstacles like discrimination of CSR strategies, lack of transparency and dearth of innovation. Some of the positive outcomes that can arise through adoption of CSR have listed. It is noticed that the hospitals implemented CSR to create goodwill, loyalty and image building. Altruism is the biggest incentive for CSR practices in hospitals. 'The CSR is useful for social mapping and corporate commitment and a tool of improving corporate positioning'.
\end{abstract}

Keywords: CSR practices, Philanthropy, Ethic, Brand image, Community.

\section{Introduction}

Health-care service is vital part of our life. Since the last 2 decades healthcare services in India has witnessed rapid growth and development. Multi-specialist/ super-specialist corporate hospitals are playing key roles in Indian healthcare service sector. Currently the country can boast of approximately 13,550 hospitals, 27,400 dispensaries, $7,17,860$ registered medical practitioners, 4,95,000 nurses, 2,27, 000 auxiliary nurses. Indian health care industry is growing at a rate of $12 \%$ p.a. The CSR is no longer optional for health care services. As a professional ethics the healthcare centres should observe the CSR practices for the welfare of community and to improve quality of life. "Corporate hospitals should be responsible and accountable in their functioning ... performance or interactions at every level of society... Social and environmental stability will follow." says Jasbir Grewal, Head, Fortis Healthcare.

The CSR could play a major role for healthcare service sector to improve their image and enhance the stakeholder engagement. The new age corporate hospitals has to understand what CSR means and how \& why to initiate CSR practices. The present research paper is an attempt to explore the CSR practices as a philanthropy activity and investigates CSR practices for long-term sustainability and creation of positive images of health care centres \& its use for environment safety \& social welfare.

\subsection{Conceptual Framework of CSR}

"CSR is way to achieve a balance or integration of economic, environmental and social imperatives. CSR is about meeting the current needs and ensuring the future generations about social safety. CSR has emerged as an inescapable priority for business leaders and a response to new conditions, challenges and aspects of ethics. Its aims to achieve overall sustainability considering the economic, ecology and social aspects so as to maximize and safeguard profit, planet and people.”[ Ebner\& Baumgartner, 2006.]
The CSR refers to participation of business focusing benefits to the society. The CSR is corporate self-regulatory integrated business model. The CSR serves wider objectives i.e. increase long-term profit through positive public relations, to maintain high ethical standards, to reduce business \&legal risk and gain shareholder"es trust by taking responsibility for corporate actions. The basic principles of CSR are sustainability, accountability and transparency. There are three broad categories of CSR approaches-

1)Environment: Steps taken to reduce negative impact and to commit safe environment.

2)Philanthropy: Donating to national and local charities by giving resources, money or time.

3)Ethical labour practice: It is concerned to treating employees fairly and ethically.

The ISO 26000 certification is recognized international standard for CSR. The ISO 26000 defined a comprehensive „CSR Actions Plan“e as under:

- Environmental sustainability: It server through recycling, waste \& water management, renewable energy, reusable materials, 'greener' supply chains, reducing paper, adopting Leadership building standards.

- Community involvement: It includes raising local charities, providing volunteers, sponsoring events, employing local workers, supporting economic growth, fair trade practices, etc.

- Ethical Marketing: While ethically marketing is placing consumers a higher value without manipulation.

\subsection{Significance of CSR}

- Reduced scrutiny: Initiatives for healthy, safe and diversified environment with systematic monitoring.

- Effective use of resources: Utilization of a holistic CSR framework. It also improves use of energy, natural resources and can be save the cost. 


\section{International Journal of Science and Research (IJSR) \\ ISSN (Online): 2319-7064 \\ Index Copernicus Value (2013): 6.14 | Impact Factor (2015): 6.391}

- Supplier relations: Appropriate CSR programs can increase the attractiveness; establish a positive image and excellent publicity.

- Brand differentiation \& enhance loyalty: For customer loyalty CSR is useful tool. To earn patient trust and loyalty, they need to go beyond healthcare services and create an emotional bond with the patient.

- Reputation risk management: A hospital which has a sound CSR mechanism does not suffer from the incidence of a reputation crisis.

- Retain quality employees: Good CSR practices boosts up morale of employees and helps to increase ability and retain quality employees.

- Responsible competiveness: A hospital should take advantage and remains at the top in the competition with best practices of CSR.

- Attracting investors \& business partners: Credibility/ stakeholder trust with social, environmental \& economic performance in addition to financial performance.

- New breakthrough-PPP: Working on PPP gives them new insights and approaches to create business opportunities as well.

- Social \& governmental support: CSR practices that goes beyond regulatory compliance and gain massive support from governments and society as well.

\subsection{Review of Literature}

The review of literature explores the CSR phenomena with several perspectives. „There are two robust CSR conceptualizations - one by Corroll (1979) and other by Wood (1991) [Jamali, Mirshak, CSR Theory \& Practices in a Developing Country Context, Journal of Business Ethics, 2007]. There are three emerging aspects of CSR i.e. ,CSR no longer optional for businesses, CSR is worth for all types Hype and how to start CSR practices are major issues in present business scenario [Nicole Fallon Taylor, What is CSR? Editorial, Business News Daily, March 2016]. The conceptual model of CSR explained by Carroll differentiated between four types of corporate social responsibilities: economic, legal, ethical and discretionary. The managerial initiative \& financial gain are the key motives for the adoption of CSR. Utilization of a holistic CSR framework in hospital can result into a higher efficiency in operations and building positive image. „The usefulness of a mix of CSR perspectives economic benefits, conformance to legal and ethical expectations and philanthropic/community involvement is helpful in explaining variations in CSR orientation.(Uhlaner, 2004) ee $^{\text {ee }}$ Moover proponents however characterize CSR as essential for successful business operations and as an opportunity for business to look beyond narrow economic returns and take the wider social concern into consideration. (Jakson\& Nelson, 2004) $)^{\text {ee }}$

As far as the health care services are concerned CSR practices serve to create image and goodwill with competitive advantage as well. „A specialize training program intended to impart knowledge regarding medico responsibilities to the staff... It will help in acquiring a better efficiency vigil in services [Mali \& Mali, Effect of Self Instructional Module on knowledge regarding Medico Legal Responsibilities among Nurses ${ }^{\text {ee }}$ International Journal of Science \& Research, pp. 617]. In India the concept of „,corporate healthcare services"e as a business is comparatively new. The CSR practices are defined as social welfare especially for under-privilege class. It"s a part of social justice, ethic \& philanthropy.

\subsection{Importance of CSR for Healthcare Services}

The CSR practices play a key role in sustainable development of healthcare service sectors. It reflects in the goals, mission and strategy of organization. According to EU Commission „CSR is a concept whereby companies integrate social and environmental concerns in their business operations and in their interaction with their stakeholders on a voluntary basis. ${ }^{c e}$

The CSR serves the environment benefits, great material recyclability, better product durability\& functionability through great use of renewable resources. Integration of environment management tools into business plans including life cycle, assessment costing, environmental management standard and eco-labeling. The CSR in terms of corporate hospitals can be regarded as a form of capital stock renewal, reflecting the need to preserve natural capital (by minimising the hospital's environmental pollution), to improve social capital (by supporting the institutional framework of laws and acceptable business practices) and to invest in human capital (by empowering and training staff) ${ }^{\mathrm{ee}}$.

\subsection{Research Methodology}

1.5 (i) Objectives of Study: The paper is an original study that addresses the current gap in the understanding of issues related to CSR practices. It is an attempt to indentify key CSR practices and its evaluation on the basis of reporting standard. Thus main objectives of research are:

- To study the conceptual framework of the CSR practices

- To examine the significance, strategy \& benefits of CSR.

- To examine the CSR practices \& provide suggestions to enhance CSR in private corporate hospitals in India.

1.5 (ii) Sampling: In present research the sample consisted of total six private corporate multi- specialist corporate private hospitals from Indian Territory. These corporate hospitals adopt \& fulfill regulations given in Companies Bill 2012- Section 135 Schedule VII for CSR. These hospitals are accredited \& certified by NABL, NABH and ISO- 26000. The CSR practices implemented in sample units were studied, analyzed and presented meaningfully. For in-depth study secondary data was acquired from the official websites of sample corporate private hospitals.

1.5 (iii) Instruments\& Variables: To fulfill the objectives a structured self-designed format was developed by the present researcher. The variables related to CSR practices and its impacts like awareness, practices, implementation of Act, act of philanthropy \& image building, etc. were observed. The CSR approaches \& Action Plan (ISO 26000) based observations were investigated.. The study is qualitative and descriptive in nature.

1.5 (iv) Hypotheses: 'There are positive initiatives \& implementations of CSR practices by Indian private 


\section{International Journal of Science and Research (IJSR) ISSN (Online): 2319-7064 \\ Index Copernicus Value (2013): 6.14 | Impact Factor (2015): 6.391}

corporate hospitals which contribute significantly for philanthropy and social welfare.'

1.5 (v) Data Collection: The data was collected from secondary sources like books, journals, government reports and from several websites. The policy and practices of CSR initiatives by hospitals are available on websites of concerned hospitals. This data was analyzed and interpreted in the light of objectives of present research paper.

1.5 (vi) Scope \& Limitations: Due to time constraint present research work was conducted on a sample of six corporate private hospitals. The study refers the purposive sample. One can ${ }^{\text {ec }}$ deny the errorless notation of secondary data and its intention was also differ from the present research.

\subsection{Analysis, Interpretation \& Discussion:}

„The CSR is a concept whereby companies integrate social \& environmental concerns in their business operations \& interaction with their stakeholders on a voluntary basis [EU Commission Report (2002)]. The diagrammatic representation of the CSR practice examined in present research is as follows:

Environmental Sustainability

Private Corporate Philanthropy \& Community

Hospitals Community Involvement (Local \&Rural)

Ethical - Labour Practices \& Marketing

\section{Case Studies of Corporate Private Hospitals:}

\section{1) Apollo Hospital, Chennai}

Apollo hospital is commitment to social responsibility and pursuit societal good through inclusive healthcare to poor regardless of geographic location. Apollo hospitals have CSR activities in following category:

Rural Development: Apollo hospitals have formed "Total Health", a non-profit organisation. It under takes activities like providing safe drinking water, extension of sanitation facilities, setting up of Nutrition Centres, Vocational Training Centres for skill development, \& mobile medical units. Apollo provides safe drinking water more than 14,000 people, Extension of sanitation facilities to 357 families, running Nutrition centres to $120+$ mothers with periodical health check-up and medical counselling, Vocational training centres facilitating skill training to more than 150 women, Mobile clinic extending community health care services to more than 30,000 people also promotion and revival of rural sports programmes in 11 villages to inculcate a healthy environment among the youngsters.

Education: Aragonda Apollo Medical Educational Research Foundation (AAMERF) has main objects to construct, maintain, run, aid and manage any association or institution, colleges and schools solely for educational purposes on a not for profit basis including scientific, medical and technical fields of education. The trust runs a primary school in Chittoor district which provides quality education to the rural community.
Healthcare: Apollo hospital runs free medical clinics at different centres in Kerala for the treatment to the poor and needy persons at free of cost.

\section{2) Nanavati Super Specialist Hospital, Mumbai}

The mission of Nanavati hospital is ,ensure care with integrity and ethics provide quality care to all section of society. "For community service Nanavati hospital aims to spread message of wellness and prevention conducts ,free health talks and screening comps ${ }^{\text {ee }}$. Following are major CSR practices of Nanavati hospital:

- Free lectures on health care at schools to informing about prevention measures for epidemics \& seasonal diseases.

- Conducts regular free continuing medical education (CME) for doctors \& training to nurses.

- The nuns of Asha Daan (of Mother Teresa) regularly bring ailing children to the hospital for free medical treatment.

- Free treatment to patients under indigent -weaker section.

\section{3) Lilavati Hospital \& Research Centre, Mumbai}

The social service wing ,SEWA ${ }^{\text {ce }}$ of the Lilavati hospital conducts several CSR activities. It serves to the health requirements of needy people with various social activities like free OPD, services to senior citizen, mobile van service to Adivasi area with continuous free health check up camps. The Roshani Eye Bank managed by hospital is a well equipped comprehensive centre for cornea removal, processing, storing, supplying and corneal transplantation.

- Almost free OPD with free medicines or at Rs. 20.

- SEWA -NAAN-NANI - Healthcare facility at NN Parks at Juhu, Versova \& Girgoan Chowpatty where regular free check-up of BP\& Sugar, free medical advice, free general \& cardiac health care camps for senior citizens.

- SEWA-Mobile-Clinic- 2 mobile vans visits areas around Mumbai \& Virar for free health consultancy.

- Roshni Eye Bank was conduct various talks \& slide shows, senior citizen clubs \& corneal grafting Diagnostic camp, Blindness control program, etc.

- Organised „Children ${ }^{\text {ee }}$ Orthopaedic Camp ${ }^{\text {ee }}$ for poorest section of society.

- Health check-up camp at schools, police stations, Dharavi camp and Senior citizen camp.

- For „save \& empower girl child ${ }^{e e}$ Mega event with collaboration of Bollywood, eminent players \& persons.

\section{4) Hiranandani Hospital, Mumbai}

With a mission „To be preferred choice for healing and good health ${ }^{\text {ee }}$ Hiranandani hospital set a vision for a long term „To create 3 established centre of excellence into the leading centre in the city / country by year $2021^{\text {ce }}$. The hospital own „Best Healing Environment Award Winner (2012) ee $^{\text {for }}$ its extra ordinary social contribution. The CSR practices of Hiranandani hospital are:

- Hospital has a special commitment to serve the disabled, free health check-up annually for the beneficiaries.

- Walkathon for „Breast Cancer Awareness ${ }^{\text {ee }}$.

- AIDS awareness programs on World AIDS Day

- Inter-school Debate on health issues since 2004.

- Run Pawai Run for awareness about the benefits of exercise \& conducts health \& happiness brand survey. 


\section{International Journal of Science and Research (IJSR) \\ ISSN (Online): 2319-7064 \\ Index Copernicus Value (2013): 6.14 | Impact Factor (2015): 6.391}

\section{5) Breach Candy Hospital Trust, Mumbai}

The CSR policy of Breach Candy hospital is ,here whatever hour you come, you will find light \& help\& human kindnesses with the objective ,to support the needs of underprivileged sections of the society. " The CSR Committee is working to recommend projects\& formulate monitoring mechanism to implement CSR projects. Breach Candy Hospital gives the amount to Indian Red Cross Society for CSR project for rural villages eradicating malnutrition, reducing infant and maternal mortality promoting wellness and supporting livelihood projects for mitigating Jaoli and Wai taluks of Maharashtra.

\section{6) Hinduja Hospital: Mumbai}

Hinduja Hospital received ,Excellence Award for CSR Project $^{\text {ee }}$ for the year 2012 out of the 363 entries from 12 countries. Hospital also awarded for its relentless service to rural community which work on core theme „Live to give hope. "Advanced mobile hospital units for tribal outskirts of Mumbai served over 40,000 people, trained more than 15 teachers and over 10,000 children in hygiene and preventive health behaviour. Hinduja hospital organises eye check-up camps. Mobile hospital unit vehicles cherished part of the lives of villagers and are economically challenged.

\section{Major Findings}

\subsection{Finding Concerned to Case-study}

- Apollo hospital has remarkable CSR practices which mainly focus philanthropy by providing health care services with the unique plan of action on three fronts. The CSR practices implemented by Apollo cover huge area and large number of poor people. Apollo deserves appreciation for its great contribution for environment, community involvement and philanthropy. But it doesn't speak about ethical labour practices and silent about ethical marketing concept.

- The mission statement of Nanavati hospital shows high philanthropy culture. The hospital has given due importance to community involvement and philanthropy, but absent towards environment sustainable program \& ignorance about environment, ethical labour practices and ethical marketing.

- Health care is focal point of CSR practices observed by Lilavati Hospital. Hospital has given higher importance to philanthropy. But due importance is needed to give towards environment, ethical labour practices and ethical marketing. One has to appreciate a full range of program for health care placed by Lilavati which covers every stage of life i.e. from childhood to old age. All the CSR practices are conducted through its wing ,SEWA ${ }^{c e}$

- Hiranandani Hospital serves both environment \& philanthropy, collaboration with NGO \& has community involvement for CSR practices. The Hiranandani hospitals have recorded price winning performance and bagged several prizes for best CSR practices. But this hospital is also silent about labour welfare and ethical marketing.

- Breach Candy Hospital also takes the collaboration of NGO for promoting CSR practices i.e. Red Cross Society. Hospital provides healthcare services and health education to poor. No record found for labour welfare and ethical marketing.
- Hinduja hospital is also one of the leading and prize winning CSR practitioner. The rural health programs for poor people are at the agenda of Hinduja hospital. It requires focusing on environment and labouring ethical practices.

\subsection{General Findings}

- Philanthropy \& social welfare: All the hospitals practicing CSR were based on philanthropy. Altruism was the biggest incentive for hospitals. It includes monetary donations and aid to non-profit organizations and communities for social welfare and environment safety.

- Benchmark: Basically CSR benefits are hard to quantify and difficult to correlate with social, environmental and financial performance. For the CSR benchmarking is needed to assess CSR, its implementation and effectiveness. Need to review competitors \& evaluating impact of CSR on society and environment.

- Role of health personnel: The major obstacles in CSR were un-trained human resource, lack of knowhow \& time constraints. Awareness of CSR is needs among health personnel. Training to HR has emerged as essential factor.

- Goodwill creation: The CSR improved the reputation; create positive image, goodwill, \& loyalty. None of the sample units adopts CSR for any financial benefits.

- Strategy: Need to pay attention by the hospitals towards CSR and should frame strategy for policy implementation.

- Trust: Trust building between units and local community is keys to success of any CSR initiative at local level.

- Acceptance: Most of the hospitals accepted CSR practice as a part of their day to day working.

- Obstacles to maintain CSR practices: The study examined problems faced by the corporate private hospitals in implementing CSR. These obstacles are lack of trained HR, lack knowledge about CSR and time constraints in implementing CSR policies, etc.

- Lack of appropriate guidelines: Non-availability of appropriate guidelines is major reason of failure of CSR initiatives and practice.

- Narrow representation: NGOs and Governments usually possess a narrow outlook towards CSR. It resulted into that to decide whether they should participate in such actives.

- Lack of participation of NGO: It is also reported that there is non-availability of NGO in remote and rural areas that can assess the identity real needs of community and work along with hospitals to ensure successful implementation.

\section{Conclusion}

We live in the millennium age, where boundaries to the organisations turning global and business are not only a profit-making proposition but social act of mankind. This character of business has brought CSR in limelight and it has gained immense prominence and popularity in the decisionmaking world. The CSR refers to business initiatives that benefits society in terms of welfare. The perception of CSR is ever changing concept. It is slowly moving away from philanthropy to a social welfare. 


\section{International Journal of Science and Research (IJSR) \\ ISSN (Online): 2319-7064 \\ Index Copernicus Value (2013): 6.14 | Impact Factor (2015): 6.391}

The concept of CSR is now firmly rooted on the agenda of hospital services. But in order to move it from theory to action there are many obstacles like discrimination of CSR strategies, lack of transparency and dearth of innovation. Some of the positive outcomes that can arise through adoption of CSR are: enhanced brand image and reputation, increase customer loyalty, improve performance, great productivity and quality, more ability to retain employees, reduced regulation, workforce diversity, feel good factor, benefits to the community and general public, charitable contribution of employees as volunteer in programs, their involvement in community education and social welfare, environment safety, greater material recyclability, greater use of renewable resources, etc.

It is noticed that the hospitals implemented CSR to create goodwill, loyalty and image building. Altruism is the biggest incentive for CSR practices in hospitals. 'The CSR is useful for social mapping, corporate commitment and a tool for improving corporate positioning'.

\section{Suggestions}

The world"es leading corporate companies agreed upon need of clarity and guidance for CSR in practice. The present research draws attention towards the issue of CSR practices related to healthcare sector. The findings of this study highlight new insights of CSR practices in the healthcare sector in Indian context from the perspective of stakeholders. In Indian private corporate hospitals the CSR exist more than the traditional philanthropy. In order to crystal gaze the future of CSR in India need to take time bound steps. Following are important suggestion for the successful implementation of CSR practices:

- Every hospital should constitute a CSR committee to recommend CSR policy i.e. schedule\& budget.

- The hospitals should create awareness about CSR among their human resource \& keep inform about CSR. Training \& encouragement for employees to join local voluntary organizations are needed for improving the CSR activities.

- CSR can successfully implement with the willingness, self-motivation and cooperation from all sections. The stakeholders should involve carry-out such activities.

- Need for creation of awareness \& publicity of CSR practice. Stakeholders \& media should including in good CSR practices. Effective bridge amongst all important stakeholders is needed with selected geographical area.

- Need to improve CSR practices towards the environment, hygiene conditions \& bio-medical waste management.

- Hospitals need to pay attention to CSR towards community. This could be done by looking into the requirements of the community. It leads to promoting overall welfare of the society. Every hospital must take into account the social, cultural and financial characteristics of the patients while fulfilling societal obligations.

- Build collaborative relationship and effective network for CSR policy implementation. Pool the resources \& build synergies to implement best CSR practices to scale up projects and innovate new once to reach out to more beneficiaries.
- Need to target needy rural people, need to public cooperation and bottom up approach.

- In order to push the development agenda in a mission mode it is recommended that realistic \& operational model of management between all three important stakeholdersGovt. , NGO and hospitals are jointly explored and addressed.

- Integration of environmental management tools into business plans, including life cycle assessment\& costing, environmental management standards and eco-labeling.

- The managerial application of CSR sensitize is the needs of community and environment. CSR enable managements to recognize that no organization exists in isolation. Through CSR organizations becomes aware that they have a responsibility towards their stakeholders. This encourages philanthropy on their part, which in turn begets them the goodwill of their stakeholders thus brining multifold benefits to the industry. It enhances the reputation of the organization, preserves the environment and promotes social welfare.

- Need to develop leverage network, counting creditability of NGO, light corporate image with right cause and more effective implementation of CSR polity. Ethical factors related to labour and marketing should involve in CSR practices of every CSR policy.

\section{Scope for Future Research}

There is a need to develop a more rational and ethical debate on CSR. CSR helps improve their image and enhance the stakeholder engagement. It can evaluate through the performance indicators for CSR mapping and studying further by focusing:

- Historical background of CSR in hospital service industry

- CSR practices prevalent in the hospitals in various states in India.

- A comparative study can be made between private \& public hospitals on CSR practices.

- Relationship between CSR disclosure \& corporate governance characters of healthcare centres

- Comparative study of CSR, value and financial performance of health service centres

\section{References}

[1] Agrawal Sanjay, Corporate Social Responsibility in India, 2008.

[2] Vasanthis V,Case Studies: CSR, pp. 113-132, ICFAI Publication, 2007.

[3] Bernhart \& Francis Maher, ISO 26000 in Practice: A User Guide, ASQ Quality Press, Wail Wisconsin, 2011.

[4] Hegde, \& other, BMWM, J Oral Maxillofac Pathol , 2007.

[5] Lars Mortins, ISO 26000, The Business Guide to the New Standard on Social Responsibility, Time Cachous Greenleaf Publishing, 2011.

[6] Bernhart\& Francis, ISO 20000 in Practice :A User Guide, ASQ Quality Press, Wisconsin, 2011

[7] Journal of Business Ethics, Nether lands, 2004

[8] Journal of Indian Accounting Asso., Vol. XLVII(2), Dec.2015, Gwalior. 


\section{International Journal of Science and Research (IJSR) \\ ISSN (Online): 2319-7064}

Index Copernicus Value (2013): 6.14 | Impact Factor (2015): 6.391

[9] Bulletin of World Health Organisation (2002), Private Sector Health.

[10] Lars Mortis, ISO 26000- The Business Guide of the New Standard on CSR, Time Cochins Greenleaf Pub., 2011.

[11] www.ncbi.wmncbi.nlm.nih.gov

[12] www.ijsr.net

[13] www.businessnewsdaily.com

[14] http://www.academia.edu/

[15] www.apollohospitals.com

[16] www.hindujahospitals.com

[17] www.nanavatihospitals.com

[18] www.lilavatihospitals.com

[19] www.breachcandyhospitals.com

[20] www.hirnandanihospitals.com

\section{Author Profile}

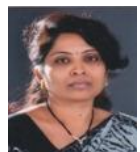

Dr. Arundhati S. Ninawe is Associate Professor \& HoD, Smt. L.R.T. College of Commerce, Akola (Maharashtra) Dr. Arundhati Ninawe has total 19 years teaching experience at senior college. She is recognized supervisor for Ph.D. of R.T.M.U., Nagpur, S.G. B. U., Amravati, \& N.M.U. Jalgaon. She is a Member of Board of Studies (BOS) of S.G.B. A. University, Amravati. She has presented more than 30 research papers at state, national and international conferences and seminars. The UGC Granted one Minor and one Major Research Projects are on her credit. Presently she is working on her second UGC Granted Major Research Project. She authored three books, namely „Consumer Behaviour, Perspectives of Cooperative Management \& Essentials of Communications ${ }^{e e}$. 